Gerión. Revista de Historia Antigua

ISSN: 0213-0181

\title{
El gobernador provincial y las comunidades latinas: el caso de Nemausus en Estrabón
}

\author{
Rubén Olmo López
}

Recibido: 30 de abril de 2018 / Aceptado: 14 de julio de 2018

Resumen. Propongo una nueva interpretación de Estrabón 4.1.12 y 4.6.4. En base a estos textos ambiguos se ha planteado la hipótesis de que Nemausus no estaría sometida a las órdenes del gobernador de la Narbonense. Sin embargo, no se conoce ninguna comunidad latina independiente de la jurisdicción del gobernador provincial y no existen indicios que prueben que Nemausus gozaba de un privilegio especial. Las frases de Estrabón se refieren a las 24 komai dependientes de Nemausus y es posible explicarlas dentro del marco institucional romano.

Palabras clave: ius Latii; oppida ignobilia; komai; adtributio; edicto provincial.

\section{[en] The Provincial Governor and the Latin Communities: The Case of Nemausus in Strabo}

\begin{abstract}
I propose a new interpretation of Strabo 4.1.12 and 4.6.4. In base of these ambigous texts, it has been hypothesized that Nemausus was not subjected to the orders of the governor of Narbonensis. However, no latin community is known to have been independent from the jurisdiction of the provincial governor and there are no evidences to prove that Nemausus had an special privilege. Strabo's phrases are about the 24 komai atributed to Nemausus, and it's possible to explain them within the roman institutional frame.
\end{abstract}

Keywords: Ius Latii; Oppida ignobilia; Komai; Adtributio; Provincial edict.

Sumario: 1. Introducción. 2. El contexto de la provincia. 3. Las comunidades latinas y la autoridad del gobernador provincial. 4. Una nueva interpretación del texto. 5. Conclusiones. 6. Referencias bibliográficas.

Cómo citar: Olmo López, R. (2018): El gobernador provincial y las comunidades latinas: el caso de Nemausus en Estrabón, en Gerión 36/2, 537-553.

1 Universidade de Santiago de Compostela / Université Paris Nanterre.

E-mail: ruben.olmo.lopez@usc.es 


\section{Introducción ${ }^{2}$}

En su descripción de la Galia Narbonense Estrabón realiza una breve comparación entre la colonia romana de Narbo y la colonia latina de Nemausus. Este autor señala que, si bien la primera era el gran puerto comercial de la provincia y recibía por ello una afluencia mayor de extranjeros y comerciantes, Nemausus la superaba en número de ciudadanos, dado que de ella dependían veinticuatro aldeas muy populosas y que, en virtud del ius Latii del que gozaba, quienes desempeñasen las magistraturas en la colonia accedían a la ciudadanía romana. ${ }^{3}$ A continuación, sin embargo, Estrabón añade una frase desconcertante:

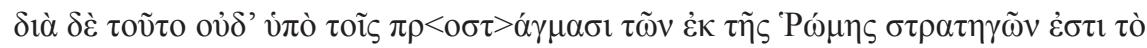

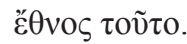

A causa de eso (¿el ius Latii?) este pueblo no está sometido a las órdenes de los gobernadores enviados desde Roma. ${ }^{4}$

Asimismo, un poco más adelante en su discurso, comenta:

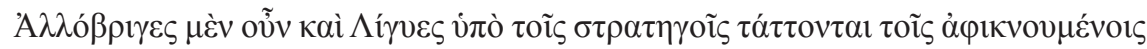

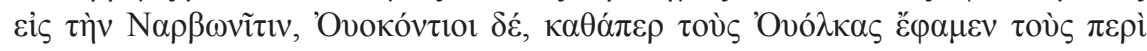

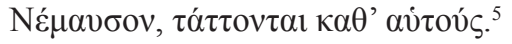

Mientras los Alóbroges y los Lígures ${ }^{6}$ dependen de los gobernadores que llegan a la Narbonense, los Voconcios, como los Volcos de los alrededores de Nemausus de los que ya hemos hablado, se administran a sí mismos.

A partir de ambos comentarios sobre Nemausus se ha planteado que o bien el ius Latii garantizaría a esta comunidad autonomía frente al gobernador, ${ }^{7}$ o bien que Augusto habría concedido esta autonomía excepcional a la colonia latina en el marco de su potenciación como centro regional. ${ }^{8}$ Sin embargo, no existe ninguna prueba más de esa hipotética concesión imperial ni tampoco de que el ius Latii pudiera conllevar tal privilegio. Las únicas comunidades que no estaban sometidas al imperium de los

2 Quiero agradecer a Estela García Fernández, Pedro López Barja de Quiroga y Simone Sisani que generosamente hayan dedicado parte de su tiempo a discutir conmigo algunos aspectos de mi hipótesis. Sus comentarios sin duda han enriquecido mi reflexión. Evidentemente, los errores que se puedan hallar en estas páginas son responsabilidad mía.

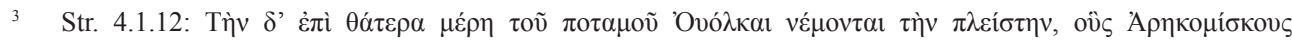

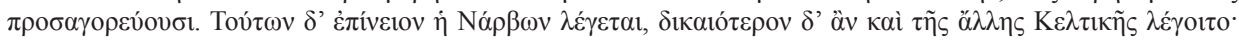

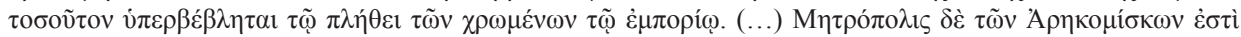

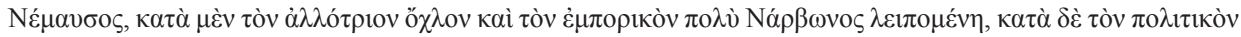

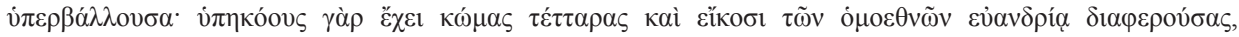

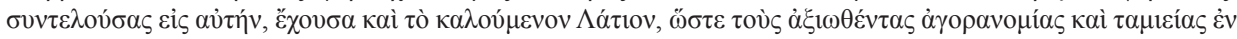

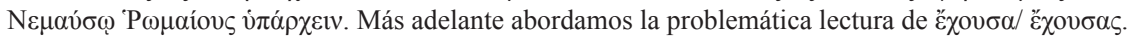

4 Las traducciones son del autor.

5 Str. 4.6.4.

6 Acerca del uso del etnónimo Ligyes en Estrabón y su paralelo latino Lígures: Thollard 2009, 130-140.

7 Bats 2007, 60, n. 32 .

8 Goudineau 1976, 111-113; Christol - Goudineau 1987, 98; Christol 1999, 21; Ferdière 2005, 151; Thollard 2009, 173. 
gobernadores provinciales eran las civitates liberae et foederatae, ${ }^{9}$ y Nemausus no era una de ellas. ¿Cómo se pueden explicar, pues, las palabras de Estrabón? En las siguientes páginas queremos proponer una nueva interpretación de estos complejos pasajes, intentando encajar estas noticias dentro de la lógica institucional romana.

\section{El contexto de la provincia}

Antes de nada, es necesario que nos detengamos brevemente en el contexto de las comunidades latinas de la Narbonense y la situación de Nemausus como metrópolis de los Volcos Arecómicos.

Se admite que las comunidades de la Galia Narbonense comenzaron a recibir el ius Latii a partir del 49 a.C. por obra de Julio César. ${ }^{10}$ Estas comunidades pasaron a ser colonias latinas y en ellas se habría aplicado el expediente inaugurado por Pompeyo Estrabón en la Transpadana en 89 a.C. ${ }^{11}$ Una de estas comunidades fue Nemausus, que presenta una evolución compleja. Pompeyo Magno había concedido a Massilia el territorio de Nemausus, al igual que el de otros oppida de los Volcos Arecómicos, en régimen de adtributio. ${ }^{12}$ Julio César puso fin a este privilegio de Massilia como castigo por haberse posicionado al lado de su rival. Aunque la adtributio no implicó el sometimiento jurídico de estas comunidades a Massilia, no cabe duda de que la decisión de César de castigar a la ciudad griega con la pérdida del importante territorio del que se beneficiaba económicamente provocó asimismo el fin de la preeminencia que ésta tenía en la provincia y favoreció el desarrollo de las colonias latinas que fueron creadas en ese mismo momento. ${ }^{13}$

Según una hipótesis que ha tenido mucho seguimiento, antes de acceder al título de colonia estas comunidades a las que se concedió el ius Latii en época cesariana habrían pasado por una breve fase en la que se denominaron oppida Latina, condición de la que se hallarían reminiscencias en el elenco de Plinio el Viejo y que sería una característica distintiva de la Narbonense. ${ }^{14}$ Según M. Christol y C. Goudineau, las deducciones que Tiberio Claudio Nerón realizó poco antes del asesinato de César en diversas colonias romanas de la provincia como Narbo Martius y Arelate ${ }^{15}$ también habrían afectado a la comunidad latina de Nemausus, que en ese momento habría recibido el título de colonia atestiguado en la leyenda de sus conocidas acuña-

Las civitates liberae conocidas son peregrinas. Sobre este concepto: Sherwin-White 1973, 174-189.

Christol - Goudineau 1987, 90; García Fernández 2001, 34; Bats 2007, 60.

Ascon. In Pis. 3 C. Cf. García Fernández 2001, 13-29; Bandelli 1990, 251-277; Luraschi 1979, 143-214.

Caes. BC 1.35. Se trataría de una adtributio con contenido menos técnico que el propuesto por Laffi 1966. Cf. Bertrand 1991, 125-164; Christol - Goudineau 1987, 88-89; García Fernández 2000b, 118-121; Bats 2007, 5859.

13 Ebel 1976, 99-105; García Fernández 2001, 37 y 56. Como bien ha señalado esta autora, "es significativo que un número importante de las comunidades latinas citadas por Plinio estuvieron antes del episodio cesariano vinculadas a Marsella de una u otra forma, bien como poleis Massalias en condición privilegiada (...), bien en condición de régimen de territorio tributario como los Volcas Arecomicorum (...)". Véase también Roth-Congès 2003; Bats 2007, 59-60.

14 Plin. HN 3.36-37; Chastagnol 1995, 92-94; Christol - Goudineau 1987, 90-91. Se ha tratado también de identificar determinados asentamientos arqueológicos con estos oppida Latina. Cf. Roth-Congés 2003, 549-564; Assénat 2010, 59-82.

15 Suet. Tib. 4: Pater Tiberi, Nero, quaestor C. Caesaris Alexandrino bello classi praepositus, plurimum ad victoriam contulit. Quare et pontifex in locum P. Scipionis substitutus et ad deducendas in Galliam colonias, in quis Narbo et Arelate erant, missus est. 
ciones con la figura del cocodrilo. ${ }^{16}$ Asimismo, estos dos autores interpretan el pasaje de Estrabón que nos ocupa de la siguiente manera: en época augustea Nemausus se consolidaría como la metrópolis de la confederación de los Volcos Arecómicos y de ella dependerían el resto de sus comunidades, que habrían sido "desclasadas". Esa sería la razón de que Estrabón las denomine komai y Plinio oppida ignobilia. ${ }^{17}$ Este último término implicaría que tales comunidades carecían de la personalidad jurídica que habían tenido como oppida Latina ahora que estaban sometidas política y económicamente a Nemausus. Sus habitantes, sin embargo, conservarían el derecho latino, pero sólo podrían acceder a la ciudadanía romana desempeñando las magistraturas en Nemausus. Esta ciudad sería favorecida por Augusto, conociendo un importante desarrollo urbano y pasando a llamarse Colonia Augusta Nemausiensium. ${ }^{18}$

La hipótesis sobre los oppida Latina ha sido rebatida por E. García Fernández, mostrando que tal concepto carece de base documental a excepción de los listados de Plinio -quien, sin embargo, utiliza también y a menudo el término oppidum para referirse a colonias y municipios romanos sobre los que no cabe duda alguna. ${ }^{19} \mathrm{La}$ documentación epigráfica y numismática no menciona tales oppida Latina, sino que hace referencia a las categorías jurídico-administrativas tradicionales: colonias, municipios, civitates o res publicae. Además, la aceptación de una difusa fase intermedia en la asunción del derecho latino por parte de las comunidades afectadas complica innecesariamente la historia constitucional de las mismas, situándolas en una condición jurídica no atestiguada y de difícil definición (a medio camino entre el status peregrino y la promoción). Así pues, tras el término pliniano de oppida Latina sólo puede hallarse una de estas dos realidades jurídicas conocidas: colonias o municipios latinos..$^{20}$ En efecto, resulta más sencillo entender que las comunidades de la Narbonense a las que César concedió el ius Latii pasaron a ser directamente colonias latinas, lo que en la práctica las habría dotado de un marco cívico contrastado en las fuentes y de probada funcionalidad administrativa.

En lo que respecta al caso particular de Nemausus, García Fernández plantea que los oppida ignobilia dependientes de esta colonia en régimen de adtributio serían comunidades peregrinas sin más y no comunidades latinas desclasadas. ${ }^{21}$ Plinio menciona los oppida ignobilia al final del elenco de comunidades de la Narbonense, y nada indica que deban incluirse forzosamente entre los oppida Latina que menciona desde 4.37. En efecto, el uso de la conjunción adversativa 'vero' parece indicar que Plinio está haciendo una inflexión en su discurso, y es sabido que tiende a presentar narrativamente las comunidades siguiendo un orden jerárquico en función de su status jurídico. ${ }^{22}$ A esto hay que añadir que el rasgo característico de la latinidad

16 Goudineau 1976; Christol - Goudineau 1987, 90-92; Christol 1989, 87-88.

17 Plin. HN 3.37: oppida vero ignobilia XVIIII, sicut XXIIII Nemausiensibus adtributa.

18 Christol - Goudineau 1987, 97-99; Christol 1989, 88, y 1999, 14; Darde 2005, 38-43 y 52-53; Thollard 2009, 175-188. Véase también la recopilación de artículos sobre la Galia Narbonense de Christol 2010.

19 Cf. Beltrán Lloris 1999, 247-267.

20 García Fernández 2001, 112-124. Christol 1999, 15, admite que tras el término de oppida Latina pueden hallarse colonias latinas.

21 En este sentido, Sherwin-White 1973, 368, pensaba que el territorio de los Volcos Arecómicos estaría ocupado por pagi (equivalente latino de komai). También critica la hipótesis del "desclasamiento" Bats 2007, 60.

22 García Fernández 2001, 60-61. También ha señalado el orden jerárquico en la descripción pliniana Roth-Congès 2003, 552 . 
provincial es el ius adipiscendi civitatem Romanam per magistratum, ${ }^{23}$ pero Estrabón precisamente señala que las komai dependientes de Nemausus carecían de él y sus élites sólo podían desempeñar magistraturas en esa ciudad. ${ }^{24}$

Esta circunstancia beneficiaría al cuerpo de ciudadanos de Nemausus, que se nutriría de un importante número de nuevos ciudadanos. A este respecto, García Fernández ha interpretado con acierto que cuando Estrabón dice que Nemausus tenía más ciudadanos que la colonia romana de Narbo se estaría refiriendo a que tenía más ciudadanos romanos potenciales entre los miembros de su oligarquía (los optimi et locupletissimi) que ésta, en virtud del acceso a la civitas Romana que ofrecía el ius Latii a los notables de las numerosas komai dependientes de Nemausus. ${ }^{25}$ En lo que respecta a las magistraturas mencionadas por Estrabón, la epigrafía de Nemausus confirma la existencia de dos tipos de carreras distintos: por un lado, una inferior constituida por la cuestura o la edilidad (que daban acceso a la civitas Romana); por otro, la de los praefecti vigilum et armorum y quattuorviri, magistraturas consideradas superiores. ${ }^{26}$

\section{Las comunidades latinas y la autoridad del gobernador provincial}

Las comunidades latinas como Nemausus, pues, gozaban de una organización cívica que las dotaba de autonomía para administrar sus asuntos cotidianos, y sus habitantes podían servirse de importantes derechos como el commercium o el conubium, que dotaban a sus relaciones sociales de un reconocimiento jurídico romano. ${ }^{27} \mathrm{Con}$ el tiempo, como muestran las leyes de los municipios flavios de la Bética, el ordenamiento interno de las comunidades latinas más desarrolladas cívicamente se fue uniformizando según principios propios del derecho romano, alcanzando una organización jurídica compleja. ${ }^{28}$ Ahora bien, entre los privilegios de que gozaban las comunidades provinciales que tenían ius Latii nunca se halló la independencia respecto a la autoridad de los gobernadores; es decir, nunca quedaron fuera de la provincia de estos magistrados. En concreto, el texto estraboniano se refiere a $\tau 0 \tilde{\varsigma} \varsigma \pi \rho<0 \sigma \tau>\alpha ́ \gamma \mu \alpha \sigma 1$

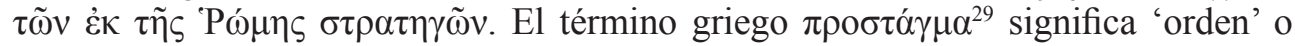
'mandato' y en el caso de los magistrados romanos a veces se emplea en las fuentes como equivalente del latino edictum. ${ }^{30}$ Es decir, Estrabón estaría diciendo que los nemausenses no estaban sometidos a las órdenes, actuaciones o edictos (habla en plural) de los procónsules de la Galia Narbonense, algo difícilmente admisible.

Christol y Goudineau plantearon la hipótesis de que Nemausus gozaría de una libertas parangonable a la de las civitates foederatae. ${ }^{31}$ En 4.6.4 Estrabón señala que

23 Ascon. In Pis. 3 C; lex Irnitana, cap. 21. Cf. Luraschi 1979, 301 y 316-329 (modo de aplicación); Lamberti 1993, 26-32 y 276-277; García Fernández 2001,15, n. 5.

24 Str. 4.1.12; García Fernández 2001, 60 y 150, n. 49; Chastagnol 1995, 92-93; Sherwin-White 1973, 112.

25 García Fernández 2001, 59.

26 Christol - Goudineau 1987, 98, n. 48; Gascou 1997, 110-114; Bats 2007, 57; Sisani 2018.

27 Sherwin-White 1973, 109-110; Kremer 2006, 9-30.

28 García Fernández 2001, 166-180.

29 Como se puede observar, se ha realizado una corrección sobre la versión del manuscrito más antiguo conservado (del siglo X), admitida por todos los editores actuales, al precisar más el sentido de la oración. Aun así el original $\pi \rho \alpha ́ \gamma \mu \alpha$ se adecúa bien al sentido, pues se refiere a la actuación o las acciones del procónsul.

30 Liddell - Scott 1968, 1526.

31 Christol - Goudineau 1987, 98, n. 50. 
los Voconcios se gobernaban a sí mismos como los Volcos de Nemausus y sabemos por Plinio el Viejo que la civitas Vocontiorum era foederata. Pero no existen noticias de que Nemausus fuese una civitas foederata en ningún momento de su historia. Tampoco de que se le concediera ningún privilegio especial en este sentido a los Volcos Arecómicos. En los últimos años, otros autores han tocado esta cuestión pero no han logrado explicarla de manera satisfactoria: M. Bats piensa que "le statut de droit latin suffit, selon Strabon, pour délivrer une autonomie face au gouverneur de la province au même titre que le foedus", ${ }^{32}$ mientras que D. Kremer señala que "les actes du gouverneur provincial devaient être soumis à l'accord des autorités nîmoises". ${ }^{33}$ ¿Estamos, pues, ante un callejón sin salida?

En las fuentes no se halla ningún ejemplo de una colonia ni de un municipio (romanos o latinos) que no estuviera sujeto al imperium del gobernador provincial. El único caso conocido de una colonia provincial que tenía reconocidos ciertos privilegios que limitaban la intervención de los gobernadores en sus asuntos es el de Apamea de Bitinia. Conocemos este detalle gracias a una de las cartas que Plinio el Joven dirigió a Trajano mientras fue gobernador de Bitinia-Ponto. ${ }^{34}$ En los mandata que entregó a Plinio, el emperador le encargó que revisara sistemáticamente las cuentas públicas de las ciudades de la provincia, que atravesaban por graves dificultades económicas. ${ }^{35}$ Cuando Plinio quiso revisar las de Apamea, sus magistrados le dijeron que deseaban que procediese a hacerlo, pero que ninguno de los procónsules anteriores había podido acceder a las cuentas de la ciudad dado que ésta tenía el privilegio antiguo de administrarse a sí misma autónomamente:

Cum vellem, domine, Apameae cognoscere publicos debitores et reditum et impendia, responsum est mihi cupere quidem universos ut a me rationes coloniae legerentur, numquam tamen esse lectas ab ullo proconsulum; habuisse privilegium et vetustissimum morem arbitrio suo rem publicam administrare. ${ }^{36}$

Obsérvese, sin embargo, que Plinio el Joven recalca que se trataba de un privilegio especial que tenía Apamea, sin duda anterior a su estatuto colonial como se deduce del empleo que hace del adjetivo superlativo vetustissimum. ${ }^{37}$ El propio desconcierto de Plinio ante la imposibilidad de proceder, en tanto que gobernador provincial, a la revisión de las rationes civitatis, y el hecho de que pidiera pruebas de este privilegio a los apameos, refuerza la idea de que se trataba de algo extraordinario. ${ }^{38}$ Así

32 Bats 2007, 60, n. 32.

33 Kremer 2006, 168, n. 228.

34 En calidad de legatus Augusti pro praetore provinciae Pon[ti et Bythiniae] consulari potestate (CIL V $5262=$ ILS 2927), o proconsulari potestate, según la restitución de Alföldy 1999, 221-244. Sobre la legación de Plinio: Mommsen 1873, 72-73; Vidman 1960, 42; Sherwin-White 1966, 525.

35 Plin. Ep. 10.18. La supervisión de las finanzas de las ciudades formaba parte de las competencias habituales de los gobernadores provinciales ya desde finales de la República. Véase, por ejemplo: Cic. Q. fr. 1.1.25; Att. 5.21.11; Fam. 3.8.2-4; 15.4.2. Cf. Dondin-Payre 1990, 344-347; López Barja de Quiroga 2009, 289-304; Bérenger 2014, 292-301; Olmo López 2018, 247-290.

36 Plin. Ep. 10.47.1.

37 Sherwin-White 1966, 630, comenta que "It is unlikely that Apamea had as a Roman colony a chartered right to absolute independence from proconsular interference".

38 Dado que tal revisión de las finanzas era necesaria y deseada por los apameos, en su respuesta $(E p$. 10.48) Trajano indicó a Plinio que siguiese adelante con ella, pero haciendo saber a los magistrados de Apamea que en lo sucesivo se seguirían respetando sus privilegios. Con todo, se trata siempre de la acción oficial del gobernador. 
pues, no se puede sacar una regla general a partir de este caso ni mucho menos establecer una categoría de colonias libres, inexistente en las fuentes. ${ }^{39}$

Por otro lado, se conoce la existencia de municipia libera en Occidente, particularmente en África bajo los Severos. Su naturaleza es una cuestión debatida que excede el objeto de este artículo. Baste señalar aquí que no existe ningún indicio de que tal denominación implicase algún tipo de independencia respecto al imperium del procónsul de África. El adjetivo liberum incorporado a la titulatura de estos municipios suele ser interpretado como un vestigio de la antigua condición de civitates liberae de que gozaron tales comunidades antes de ser promocionadas al estatuto municipal. Sería una deferencia que tuvo hacia ellas el poder imperial con el fin de diferenciarlas de las comunidades que hasta entonces habían sido meras civitates stipendiariae. ${ }^{40}$ Lo mismo sucede con los municipia foederata atestiguados epigráficamente en Italia. ${ }^{41} \mathrm{M}$. Humbert ha demostrado que cuando una civitas foederata se convertía en municipium y se integraba en la civitas Romana, su foedus perdía su eficacia jurídica. ${ }^{42}$

No es el caso de la colonia latina de Nemausus. Salvo los sorprendentes comentarios de Estrabón, no hay ningún indicio que permita pensar que los gobernadores provinciales no podían ejercer sobre Nemausus los amplios poderes jurisdiccionales de que estaban investidos. ${ }^{43}$ Es más, la lex del municipio flavio de Irni, en la Bética, proporciona información valiosa acerca de la intervención del gobernador provincial en el funcionamiento de las comunidades latinas.

En primer lugar, destaca la importancia otorgada al edicto jurisdiccional del gobernador. En el capítulo 85 de la lex Irnitana se establece:

R(ubrica). Magistratus ut in publico habeant album eius qui provinciam optinebit, exque eo ius dicant. // Quaecumque edicta, quasue formulas iudiciorum, quasque spon/siones, stipulationes, satis acceptiones, \{praescriptiones\} ex/ceptiones, praescriptiones, quaeque interdicta $\{i\}$ is qui ei pro/vinciae praerit in ea provincia proposita habebit, quae eo/rum ad iuris dictionem eius magistratus qui <in> municipio Fla/vio Irnitan 'o 'i (ure) d(icundo) p(raerit) pertinebunt, ea omnia is in eo munici/pio, in suo magistratu, quotidie maiorem partem cuiusque di/ei proposita proscriptaque habeto ut d(e) p(lano) r(ecte) l(egi) p(ossint), et ad ea inter/dicta, edicta, easque formulas, sponsiones, stipulationes, satis ac/ceptiones, \{esceptiones\} exceptiones, praescriptiones in eo mu/nicipio ius dicatur, iudicia dentur fiant exerceanturue, et / it quod adversus h(anc) l(egem) non fiat utique ex hac lege licebit / [fiat sine] d(olo) $m($ alo $) .{ }^{44}$

\footnotetext{
39 Como bien advirtió De Martino 1965, 676.

40 Gascou 1972, 178-180, 185-186, 189-190 y 192-194, y 1982, 210-211; Jacques 1991, 583-606. Abbott - Johnson 1926, 42-43, consideraban que hubo hasta 39 civitates liberae en África. Plin. HN 5.30 menciona la existencia de 30 oppida libera.

41 Véanse los casos de Camerino, Capena y los Tarquinienses foederati, analizados por Veyne 1960, 429-436, y Humbert 1978, 260-262.

42 Humbert 1978, 251-271.

43 Dig. 1.16.7.2-9.pr: Cum plenissimam autem iurisdictionem proconsul habeat, omnium partes, qui Romae vel quasi magistratus vel extra ordinem ius dicunt, ad ipsum pertinent et ideo maius imperium in ea provincia habet omnibus post principem, nec quicquam est in provincia, quod non per ipsum expediatur.

44 Seguimos la lectura de Lamberti 1993, 350-353, pero hemos cambiado los signos (( )) y * * usados por esta autora por \{\} $\mathrm{y}^{{ }^{r}}$, siguiendo las indicaciones del nuevo CIL II. Sobre el texto de la lex Irnitana véase también González 1986 y D’Ors 1988.
} 
El edicto jurisdiccional del gobernador era, a un tiempo, el marco y el medio de transmisión de su programa jurisdiccional, que condicionaba el funcionamiento de los municipios y colonias provinciales. Los magistrados municipales debían adecuar su actuaciones jurisdiccionales a las cláusulas del edicto provincial. Por ello, como se señala en este capítulo, debía estar expuesto públicamente en el municipio. En su edicto el gobernador exponía las regulaciones por las que se tenían que regir las relaciones jurídicas (como contratos, préstamos, herencias, etc.) y las normas procesales a seguir en los pleitos que se produjeran tanto entre los individuos como entre las comunidades de la provincia en función de su status jurídico. A este respecto, ocupaban un lugar importante los aspectos relacionados con la iudicis datio. ${ }^{45}$ Precisamente el capítulo 84 de la lex Irnitana indica que el número de jueces que actuasen anualmente en el municipio debía ser fijado por el gobernador de la provincia. ${ }^{46}$ También regulaba la elección del actor municipum. ${ }^{47}$ En el edicto provincial también se trataban cuestiones relativas a la administración de las comunidades, como las rationes civitatum..$^{48}$ Asimismo, el gobernador señalaba en él los límites de su propia jurisdicción. Estas disposiciones tenían la misma duración que el mandato del gobernador y no podían ser contravenidas por éste, ${ }^{49}$ lo que ofrecía una seguridad jurídica a quienes se veían afectados por el edicto. Estas garantías se verían reforzadas por el hecho de que las cláusulas del edicto acabaron por consolidarse y se convirtieron en traslaticias; es decir, fueron repetidas sin alteraciones sistemáticamente por cada nuevo gobernador en su edicto. Aunque una parte importante del edicto provincial estaba constituida por una trasposición del edicto urbano a la provincia -sólo dirigida, por tanto, a los cives Romani que allí se hallaran-, la parte eminentemente pro-

45 Cic. 2 Verr. 2.32-33.

46 R(ubrica). De iudicibus legendis proponendis. / Qu[i II]viri in [e]o municipio i(ure) d(icundo) praerunt de communi sententia, / aut, si u[ter eo]rum aberit, aliave quae causa ei inciderit quo / minus [eam] rem agere possit, alter, in diebus quinque proxi/[mis qui]bus iure dicundo praesse coeperit poteritque, iudi/[ces legi]to ex decurionibus conscriptisve tot quod ei videbi/[tur qui ei] provinciae praerit, qui eo anno non debebunt / [munere alio simul fu]ngi, ex reliquis municipibus qui praeter / [dec] urion[es conscriptosv] ingenui erunt tot quod ei videbitur / [q] ui ei pro[vinciae] praerit, non minores quam XXV annorum, / quibus ip[si]s quorumv[e] cui[u]s patri avove paterno proavove / patern 'o ' aut patri cuius in potestate erit non minor quam HS (sestertium) $V$ (milia)/res sit, quos maxime idoneos arbitratur l[e]gique iudices pro <re $>$ com/muni municipum eius municipi \{ese\} iuraverint coram decurionibus conscriptive non paucioribus quam decem ... (El texto prosigue indicando los requisitos que debían cumplir los jueces).

47 Lex Irnitana, cap. 70: R(ubrica). De actore municipum constituendo <deque> praemio mercede/ve eius. / Quoi quibusque mandetur permittaturve ut nomine munici/p $\{i\}$ um municipi Flaui Irnitani agant petantve quit is, aut, si cum iis agetur petetur $<v e>$ quit ab $<i i>$, nomine eorum iudicium / accipiat, decurionum conscriptorumve cognitio consti/tutioque esto, cum eorum non minus quam duae tertiae / partes ader [u]nt, d[um e] um el 'i 'gant cui per edictum eius qu'i provin/ciae praerit [p]rocu[rat]ori aut cognitori esse licebit, idemque conti/tu $<u>n t o$ quantu[m ei ei]\{u\}sve, qui municipibus municipi Flavi Irni/tani petet pet[en] t petiturus petiturive erunt petierit $<$ petierintve $>$ iudicium/ve eorum nom[i]ne acceperit acceperint accepturus erit acce[e]p/turive erunt, $p[r]$ aemi opere $\{v e\}$ nomine dari oporte $\{b\} a t$.

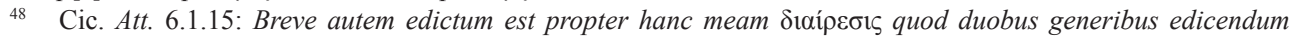
putavi. Quorum unum est provinciale in quo est de rationibus civitatum, de aere alieno, de usura, de syngraphis, in eodem omnia de publicanis; alterum, quod sine edicto satis commode transigi non potest, de hereditatum possessionibus, de bonis possidendis, vendendis, magistris faciendis, quae ex edicto et postulari et fieri solent. Tertium de reliquo iure dicundo ö $\gamma \rho \alpha \varphi \mathrm{v}$ reliqui. Dixi me de eo genere mea decreta ad edicta urbana accommodaturum. El jurista Gayo dedicó un tratado ad edictum provinciale en época antonina, del cual se conservan algunos fragmentos. Su naturaleza ha sido objeto de una importante controversia. Cf. Lenel 1927, 4-5; Martini 1969, 1-9; Valiño 1979; Guarino 1994, 294.

49 Como estableció la lex Cornelia de iurisdictione del 67 a.C.: ut praetores ex edictis suis perpetuis ius dicerent (Ascon. In Cornel. 59C). Cf. De Martino 1966b, 150; Guarino 1987, 272-273. 
vincial -lo que Cicerón denominó genus provinciale- ocupaba un lugar relevante en él y afectaba a todos los habitantes de su provincia, fuesen peregrinos o ciudadanos romanos o latinos..$^{50}$ Se trataba, por tanto, de un importante medio de romanización de los peregrinos provinciales.

Asimismo, el capítulo 85 recuerda que los magistrados de Irni deben acatar el resto de disposiciones de carácter jurídico que emanaban del gobernador (stipulationes, interdicta, etc., que formaban parte de los llamados remedios pretorios). ${ }^{51}$ Por último, aunque las leyes municipales flavias no lo expliciten, no cabe duda de que el edicto del gobernador provincial también era el referente de los duumviri iure dicun$d o$ en lo que respecta a la designación de tutores y la realización de manumisiones. ${ }^{52}$ Así pues, Estrabón, cuando emplea el término $\pi \rho 0 \sigma \tau \alpha ́ \gamma \mu \alpha$, no puede estarse refiriendo a los edictos jurisdiccionales anuales de los gobernadores. Tampoco a los otros edictos que podían publicar durante su mandato para solucionar alguna cuestión no prevista en el edicto provincial.

Al margen del edicto provincial, los amplios poderes jurisdiccionales que tenían los gobernadores provinciales se manifestaban cotidianamente tanto en el ámbito penal como en el civil. Las causas penales y, en particular, las que podían conllevar la muerte o la capitis deminutio del condenado eran competencia exclusiva de los gobernadores, únicos magistrados de la provincia que contaban con ius gladii. ${ }^{53} \mathrm{En}$ lo que respecta a los procesos civiles, el capítulo 84 de la lex Irnitana nos informa de que las causas de mayor cuantía (en su caso a partir de 1.000 sestercios) no podían ser vistas por sus magistrados y debían derivarse al tribunal del gobernador. La ley municipal le atribuye, pues, un papel tutelar: desde su posición de juez supra partes, el gobernador velaba por el mantenimiento de la paz interna en esta comunidad.

Asimismo, el capítulo 84 detalla con exhaustividad los tipos de causas que, aun estando por debajo de los 1.000 sestercios, por su naturaleza quedaban fuera de la jurisdicción de los magistrados municipales. Se trata de las causas de libertate, las acciones de vi, fiducia o mandatum, los depósitos, las tutelas, las cuestiones de dolo o fraude, el furtum cometido por una persona libre o por un esclavo con participación de su dueño, y las causas que entrañasen iniuria para una persona libre. Se trata, pues, de una amplia casuística que sólo correspondía tratar al gobernador. ${ }^{54}$

La epigrafía jurídica de la Bética nos ofrece otros testimonios valiosos acerca del modo en que los procónsules de esta provincia intervinieron en los asuntos de comunidades latinas. Entre éstos, destacan los bronces que recogen, respectivamente, la epistula Vespasiani ad Saborenses (77 d.C.) y la epistula Titi ad Muniguenses (79 d.C.). No entraremos aquí en el análisis del papel jugado por los procónsules de la Bética en los asuntos y procedimientos que ocupan ambas epistulae, cuestión que ya hemos abordado en otra sede. ${ }^{55}$ Baste remarcar que ambos documentos prueban la importante intervención de los gobernadores provinciales en las comunidades latinas dentro del ejercicio de sus competencias habituales. En estos testimonios se observa

50 Cf. Olmo López 2015, 939-967; Fournier 2010, 273-276; Peppe 1991, 14-93; Martini 1969; Pugliese 1964, 972-986; Buckland 1934, 81-96.

51 Véase el comentario de Lamberti 1993, 146-147.

52 Tutoris datio: lex Irnitana 29 = lex Salpensana cap. 29; manumisiones: lex Irnitana cap. 28 y $72=$ lex Salpensana cap. 28.

53 Dig. 1.18.6.8: Qui universas provincias regunt, ius gladii habent et in metallum dandi potestas iis permissa est.

54 Lamberti 1993, 149-167.

55 Olmo López 2017, 143-148. 
que no sólo aplicaban su jurisdicción sin restricciones especiales de ningún tipo y dentro de un sistema judicial perfectamente ordenado, sino que también ejercían una tutela sobre su sostenibilidad económica. Así, mientras que la epistula ad Muniguenses recoge una de las típicas causas pecuniarias vistas por los gobernadores (en concreto, el impago de una deuda contraída por la comunidad con un particular), la epistula ad Saborenses revela que también era requerida su intervención en los casos en que una comunidad latina recién promocionada solicitase contar con más vectigalia. En esta última cuestión, el emperador, aunque tenía la última palabra, dependía del procónsul para conocer las circunstancias de la comunidad y la posibilidad de aceptar o no su petición. ${ }^{56}$ Los gobernadores, por tanto, no sólo tenían un importante papel como máxima autoridad jurisdiccional en la provincia, sino que también actuaban como supervisores de la estabilidad económica de las comunidades latinas.

Estos ejemplos que hemos tratado sucintamente confirman que las comunidades provinciales que tenían ius Latii estaban plenamente sometidas a la autoridad del gobernador provincial y que la intervención de éste en sus asuntos era habitual. También ofrecía a estas comunidades una vía de comunicación directa con el poder imperial. Sólo las civitates liberae et foederatae no estaban, en principio, sujetas a la intervención del gobernador. Aún así no cabe duda de que éste se encargaría de señalar en su edicto de qué comunidades se trataba y cómo debían resolverse los conflictos que podían producirse entre ellas y las que sí estaban bajo su autoridad. Además, a pesar de que el gobernador no podía intervenir por iniciativa propia en las civitates liberae, sus magistrados podían pedírselo en caso de necesidad. ${ }^{57}$ En cuanto a las civitates foederatae, se sabe, por ejemplo, que en 61 a.C. Gades solicitó la intervención de Julio César, por entonces gobernador de la Hispania Ulterior, para que reorganizase las instituciones de la ciudad, que parece haber sufrido un stasis interna. ${ }^{58}$

La intervención de los gobernadores provinciales en los asuntos de las comunidades latinas y en el funcionamiento de sus instituciones representó una de las mejores manifestaciones de la tutela que el poder imperial ejercía sobre ellas. De ella se beneficiaron las comunidades latinas al igual que las colonias y municipios romanos. Los gobernadores velaron por la estabilidad y buen funcionamiento de estas comunidades privilegiadas no sólo porque estaban habitadas por ciudadanos romanos, sino porque en ellas descansaba la administración territorial básica, fundamental para el sostenimiento de un imperio poco burocratizado desde un punto de vista cuantitativo. ${ }^{59}$ Las comunidades con ius Latii, además, fueron un instrumento crucial para la integración de las élites provinciales en el marco cívico y jurídico romano.

\section{Una nueva interpretación del texto}

A nuestro juicio, hay que mover el foco de atención de Nemausus a las 24 komai atribuidas a ella, pues la frase que nos ocupa se refiere a estas últimas. Resultará útil recordar el pasaje completo de 4.1.12:

CIL II $2 / 5,871 ;$ CILA 5, 1052.

Hurlet 2006, 277-278; Millar 1999, 95-113; Galsterer 2000, 349.

58 Cic. Balb. 43: Omitto quantis ornamentis populum istum C. Caesar, cum esset in Hispania praetor, adfecerit, controversias sedarit, iura ipsorum permissu statuerit, inveteratam quandam barbariam ex Gaditanorum moribus disciplinaque delerit, summa in eam civitatem huius rogatu studia et beneficia contulerit.

59 Olmo López 2018, 245-424. 


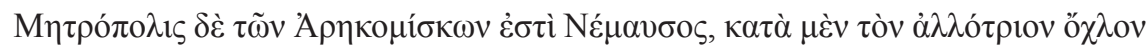

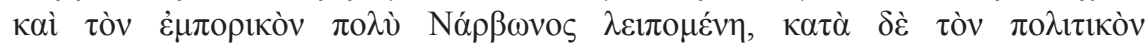

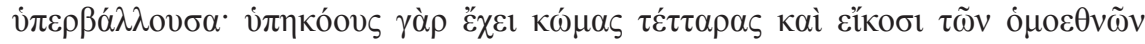

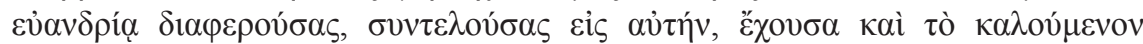

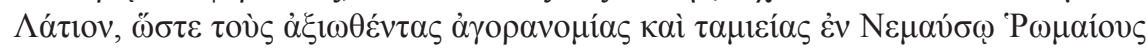

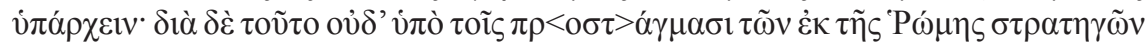

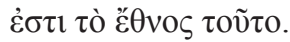

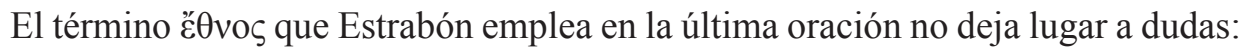
con él se está refiriendo a los Volcos Arecómicos que tenían por metrópolis a Nemau$s u s$, no a la ciudad misma. ${ }^{60} \mathrm{Si}$ aludiera a la colonia latina, desde luego la habría denominado de otro modo. Esto se ve corroborado por el pasaje de 4.6.4, en el que se

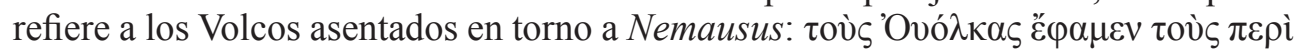

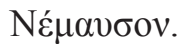

El protagonismo que tienen en el texto las 24 komai se vería reforzado si el participio del verbo Ĕ$\omega \mathrm{c}$ concordase con ellas y no con Nemausus -como suele presentarse en las ediciones modernas. Se trata de una cuestión muy debatida. La mayoría de

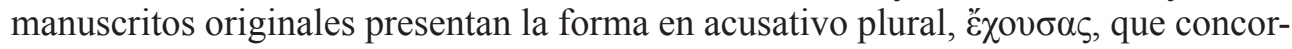
daría con $\kappa \omega ́ \mu \alpha \varsigma$. Sin embargo, se tiende a aceptar la corrección de Coray, que optó por el caso en nominativo singular (lectio difficilior) que concuerda con Nemausus. ${ }^{61}$ Lo cierto es que la forma en acusativo plural es perfectamente admisible. Ahora bien, aceptar esta lectura no implica que se haya de asumir forzosamente la hipótesis de que las 24 komai tendrían el derecho latino por sí mismas o que lo habrían conservado tras su "desclasamiento". ${ }^{2}$ Estamos de acuerdo con García Fernández en que Nemausus sería la única que había recibido el ius Latii en tanto que colonia latina. ${ }^{63}$ Sin embargo, de ese derecho latino también se beneficiaban las 24 komai atribuidas a ella y, en concreto, sus notables, contribuyendo a reforzar el cuerpo cívico de $\mathrm{Ne}$ mausus -que es lo que Estrabón quiere remarcar. Con todo, aun manteniendo la lectio difficilior de este participio ( $(₹ \chi 0 v \sigma \alpha)$, la interpretación que vamos a proponer no se ve afectada.

La clave para explicar los pasajes de Estrabón radica, a nuestro juicio, en la naturaleza de la relación de estas komai con su metrópolis: la adtributio. Como bien señaló U. Laffi, los oppida ignobilia adtributa de Nemausus carecían de autonomía jurisdiccional, de magistrados propios y, punto importante, tenían una serie obligaciones económicas hacia la colonia latina de la que dependían. ${ }^{64}$ Estos oppida ignobilia tributaban en la colonia de Nemausus y, por tanto, en ámbito fiscal no se relacionaban directamente con el procónsul u otros agentes imperiales como sucedía con otras comunidades menores que formaban parte de civitates peregrinas. ${ }^{65}$

60 Thollard 2009, 185.

${ }^{61}$ Plácido 1991, 61-62; Sherwin-White 1973, 368, n. 1. A favor de mantener la lectio facilior: Goudineau 1976, 106; Bats 2007, 51; Thollard 2009, 173-174.

62 Tampoco lo hace Bats 2007, 60.

63 García Fernández 2001, 59. Estamos de acuerdo con esta autora en que resulta débil la hipótesis de que tales komai fuesen oppida Latina desclasados que hubiesen conservado, a pesar de todo, el ius Latii.

64 Laffi 1966, 41-43.

65 Sherwin-White 1973, 367-369. Plinio el Viejo no menciona ninguna civitas stipendiaria en su elenco de comunidades de la Narbonense, lo que ha llevado a plantear su desaparición en la formula provinciae. Cf. Christol 1994, 45-63. Empero, el argumento ex silentio nunca es definitivo. 
En época augusteo-tiberiana, las civitates peregrinas de las provincias proconsulares estaban sometidas directamente al procónsul tanto desde un punto de vista jurisdiccional como en lo que atañía a la recaudación tributaria. Como es sabido, tras la reforma administrativa augustea del 27 a.C., estas provincias mantuvieron la vieja estructura de gobierno republicana, con un cuestor subordinado al procónsul que se encargaba de las cuestiones financieras. ${ }^{66}$ La introducción de los procuradores imperiales en ellas se fue produciendo paulatinamente y sólo con el tiempo acabaron por absorber todas las competencias en materia fiscal. ${ }^{67}$ En cambio, las colonias y municipios romanos y latinos gestionaban sus vectigalia por sí mismos, a través de sus magistrados. Por tanto, en esta cuestión no estaban sometidos a las órdenes ni la intervención directas del procónsul, aunque sin duda éste podía revisar las rationes civitatum y, como vimos en el caso de Sabora, desempeñaba un papel muy importante cuando una comunidad solicitaba contar con nuevos vectigalia al emperador.

Desde este punto de vista, la afirmación de que las komai de los Volcos Arecómicos de Nemausus no estaban sometidas a las "órdenes" del procónsul de la Narbonense cobra pleno sentido sin necesidad de suponer una autonomía respecto al imperium de éste. En ámbito fiscal, en efecto, dependían en primera instancia de los magistrados de la colonia. Es significativo, además, que el término griego $\alpha$ vovo $\mu i ́ \alpha$ no sea empleado por Estrabón en ningún momento. Se trata de una interpretación de algunos autores modernos. De haber contado con una autonomía completa respecto a la autoridad del procónsul, Estrabón habría usado, sin duda, la palabra exacta y no la perífrasis a la que recurrió. ${ }^{68}$

Esta explicación parece caer en saco roto por culpa del segundo pasaje problemático de Estrabón (esto es, 4.6.4). En él dice que la civitas foederata de los Voconcios, al igual que los Volcos de Nemausus, se administraba a sí misma, mientras que los Alóbroges y los Lígures sí estaban sujetos a las órdenes del gobernador de la Narbonense. Sin embargo, estas afirmaciones también encajan en la interpretación que proponemos. Los Alóbroges y los Lígures a los que se refiere aquí Estrabón son los que ocupaban el área montañosa de la Narbonense, ${ }^{69}$ donde vivían en asentamientos menores de tipo rural que carecían de organización jurídica y de magistrados. Así pues, estaban sometidos a las órdenes directas del procónsul en ámbito fiscal.

En cuanto a la comparación que establece con la civitas Vocontiorum, parece haber estado condicionada por el hecho de que los Voconcios y los Volcos Arecómicos estaban organizados internamente de una manera similar, según se desprende de Plinio el Viejo: una serie de entidades menores -oppida ignobilia (las komai estrabonianas)- dependían de un centro con verdadera entidad cívica según los esquemas romanos -en el caso de los Voconcios la civitas contaba con dos cabeceras, Vasio y Lucus Augusti. ${ }^{70}$ A este respecto, S. Sisani, en un exhaustivo artículo que está a punto de ver la luz, plantea que la denominación de la civitas Vocontiorum como foede-

66 D.C. $53.14 .5-15.6$.

67 Con todo, durante el resto del período altoimperial se seguirían produciendo interferencias entre las competencias de los gobernadores de rango senatorial y los procuradores. Cf. Tac. Agr. 9.4. Dado que los gobernadores supervisaban la elaboración del censo, la cooperación con los procuradores fue inevitable.

68 Incluso por una autonomía relativa la palabra era ya usada. Cf. Cic. Att. 6.1.15: Graeci vero exsultant quod pe-

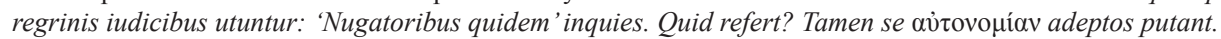

69 De hecho, luego pasa a referirse a los Lígures del otro lado de los Alpes, que formaban parte de una nueva provincia gobernada por un procurador ecuestre.

70 Plin. HN 3.37: Vocontiorum civitatis foederatae duo capita Vasio et Lucus Augusti, oppida vero ignobilia XVIIII, sicut XXIIII Nemausiensibus adtributa. 
rata no haría referencia a la base jurídica que la unía a Roma (esto es, a un foedus), sino a la organización interna de esta comunidad, estructurada como una agregación de 19 asentamientos menores encabezados por dos capita.${ }^{71}$ Esto encajaría bien con que tanto Vasio como Lucus Augusti formen parte de la lista pliniana de oppida Latina. Como bien ha argumentado E. García Fernández, no es compatible el status jurídico de civitas foederata con el ius Latii, ya que se trata de una latinidad de tipo municipalizante. De haber existido un foedus previo con Roma, lo más probable es que al recibir el ius Latii en época de César la condición federada de la civitas Vocontiorum hubiese dejado de ser efectiva jurídicamente. ${ }^{72}$ Así pues, al igual que los Volcos de Nemausus, los oppida ignobilia voconcios tributarían en estas cabeceras, que se administraban con sus propios magistrados. Ahora bien, no por ello dejaban de estar sometidos al imperium del procónsul.

\section{Conclusiones}

En estas páginas hemos querido mostrar que los ambiguos pasajes de Estrabón 4.1.12 y 4.6.4 no hacen referencia a ninguna autonomía especial de la colonia latina de Nemausus frente al imperium del procónsul de la Narbonense. Las comunidades provinciales que tenían ius Latii contaban con una capacidad de autogestión para administrar su territorio y resolver sus asuntos cotidianos, pero nunca dejaron de estar sometidas a la autoridad de los gobernadores romanos. El expediente latino provincial favoreció la paulatina integración de estas comunidades en el marco cívico y jurídico romano, lo cual implicaba forzosamente que estaban sujetas a la jurisdicción del gobernador provincial y, en concreto, a las cláusulas de su edicto. La lex Irnitana es un valioso ejemplo de la relevancia creciente que el edicto jurisdiccional del gobernador tuvo en las comunidades latinas más desarrolladas. Tampoco existen indicios de que Augusto hubiese concedido a Nemausus o a la llamada "confederación volca arecómica" ningún privilegio especial que las liberase de acatar el imperium del gobernador provincial. Por ello, en nuestra opinión, la única explicación posible de las desconcertantes afirmaciones de Estrabón es que no se está refiriendo a la metrópolis de Nemausus, sino a las 24 komai de los Volcos Arecómicos que dependían de ella en régimen de adtributio.

Estas komai carecían por defecto de un ordenamiento jurídico y de magistrados propios. Cuando formaban parte de una civitas peregrina, su tributación dependía directamente de las órdenes de los procónsules y de los subordinados que enviarían para organizarla. En cambio, las komai volcas atribuidas a Nemausus estaban sometidas en primera instancia a los magistrados de la colonia latina -algunos de los cuales eran sus propios notables-, que eran quienes se encargaban de recaudar y administrar sus vectigalia, como sucedía en toda comunidad privilegiada. No se hallaban, pues, en la

71 Sisani 2018, quien recuerda el pasaje de Plin. HN 7.78 donde se les denomina como gens foederata. Agradezco mucho al autor que me haya permitido consultar su artículo anticipadamente.

72 García Fernández 2001, 63-65, quien señala que tal mención pudo haber sido mantenida en la titulatura de la comunidad honoríficamente. Véase el caso de los municipia libera africanos o de los municipia foederata itálicos atestiguados en las fuentes (Veyne 1960, 429-436; Humbert 1978, 251-271). Como bien explica De Martino 1966a, 85: "Essendo però costituite dallo Stato romano, le colonie avevano una condizione loro particolare nascente dalla deductio, godevano di una larga autonomia, ma non sarebbe giusto assimilarle senz'altro a città libere federate, anche se gli abitanti di esse sono chiamati socii Latini nominis". 
situación que se esperaría de unas simples komai. Pero evidentemente sí que estaban sometidas al imperium del procónsul de la Narbonense. Los magistrados de Nemausus, como los del resto de comunidades latinas, debían adecuar su actuación oficial a las cláusulas del edicto provincial y acatar la autoridad del gobernador. El único privilegio particular que tenían estos Volcos Arecómicos era que sus notables, a pesar de proceder de asentamientos menores que carecían de ordenamiento jurídico, gozaban del ius adipiscendae civitatis Romanae per magistratum si ejercían las magistraturas menores en Nemausus, hecho que llamó la atención de Estrabón.

\section{Referencias bibliográficas}

Abbott, F. F. - Johnson, A. C. (1926): Municipal Administration in the Roman Empire (=AAR XXVII), Princeton.

Alföldy, G. (1999): "Die Inschriften des jungeren Plinius und seine Mission in Pontus et Bithynia", [en] Städte, Eliten und Gesellschaft in der Gallia Cisalpina. Epigraphischhistorische Untersuchungen, Stuttgart, 221-244.

Assénat, M. (2010): “Le territoire des Volques Arécomiques entre Strabon et Pline", Pallas 84, 59-82 (http://doi.org/10.4000/pallas.3355).

Bandelli, G. (1990): “Colonie e municipi delle regione transpadane in età repubblicana", [en] La città nell'Italia settentrionale in età romana, Roma, 251-277.

Bats, M. (2007): "Droit latin, adtributio et contributio. Strabon, Pline, Nîmes et les Volques Arécomiques", MEFRA 119/1, 51-62 (https://doi.org/10.3406/mefr.2007.10325).

Beltrán Lloris, F. (1999): “Municipium c. R., oppidum c. R. y oppidum Latinum en la NH de Plinio. Una revisión del problema desde la perspectiva hispana”, [en] J. González (ed.), Ciudades privilegiadas en el Occidente romano, Sevilla, 247-267.

Bérenger, A. (2014): Le métier de gouverneur dans l'empire romain. De César à Dioclétien (=De l'archéologie à l'histoire 62), Paris.

Bertrand, J.-M. (1991): "Territoire donné, territoire attribué: note sur la pratique de l'attribution dans le monde impérial de Rome", CCG 2, 125-164 (https://dx.doi. org/10.3406/ccgg.1991.1337).

Buckland, W. W. (1934): "L'Edictum provinciale", RHDFE, 81-96.

Chastagnol, A. (1995): “À propos du droit latin provincial”, [en] La Gaule romaine et le droit latin. Recherches sur l'histoire administrative et sur la romanisation des habitants (=Scripta varia 3), Lyon, 89-112.

Christol, M.

(1989): “Le droit latin en Narbonnaise: L'apport de l'épigraphie (en particulier celle de la cité de Nîmes)", [en] Les inscriptions latines de Gaule Narbonnaise (=Travaux du Centre Camille Jullian 3), Nîmes, 87-100.

(1994): "Pline l'Ancien et la formule de la province Narbonnaise", [en] La mémoire perdue: À la recherche des archives oubliées, publiques et privées, de la Rome antique, Paris, 45-63.

(1999): "La municipalisation de la Gaule Narbonnaise", [en] M. Dondin-Payre - M.-Th. Raepsaet-Charlier (eds.), Cités, municipes, colonies. Le processus de municipalisation en Gaule et en Germanie sous le Haut-Empire romain (=Histoire ancienne et médiévale 53), Paris, 1-27.

(2010): Une histoire provinciale: La Gaule Narbonnaise de la fin de IIe siècle av. J.-C. au IIIe siècle ap. J.-C. Scripta varia (=Histoire ancienne et médiévale 103), Paris. 
Christol, M. - Goudineau, C. (1987), "Nîmes et les Volques Arécomiques au Ier siècle avant J.-C.”, Gallia 45, 87-103 (https://doi.org/10.3406/galia.1987.2881).

Darde, D. (2005): Nîmes antique (=Guides Archéologiques de la France 40), Paris.

De Martino, F.

(1965): Storia della costituzione romana IV, Napoli.

(1966a): Storia della costituzione romana II, Napoli.

(1966b): Storia della costituzione romana III, Napoli.

Dondin-Payre, M. (1990): "L'intervention du proconsul d'Afrique dans la vie des cités", [en] L'Afrique dans l'Occident romain (Ier s. av. J.-C.-IVe s. ap. J.-C.), (=Collection de l'École française de Rome 53), Roma, 333-349.

D’Ors, A. - D'Ors, X. (1988): Lex Irnitana (Texto bilingüe), (=Cuadernos Compostelanos de Derecho Romano 1), Santiago de Compostela.

Ebel, Ch. (1976): Transalpine Gaul: The emergence of a roman province (=Studies of the Dutch archaeological and historical society 4), Leiden.

Ferdière, A. (2005): Les Gaules: Provinces des Gaules et Germanies, Provinces alpines (IIe siècle av.-Ve siècle ap. J.-C.), Paris.

Fournier, J. (2010): Entre tutelle romaine et autonomie civique. L'administration judiciaire dans les provinces hellénophones de l'Empire romain (129 av. J.-C. - 235 apr. J.-C.), (=BEFAR 341), Paris-Athènes.

Galsterer, H. (2000): "Local and provincial institutions and government", CAH XI, 344-360.

García Fernández, E.

(2000a): "Plinio y los oppida stipendiaria. A propósito de un artículo de Alicia M. a Canto", Gerión 18, 571-591.

(2000b): “Immunitas y adtributio", [en] F. J. Sánchez-Palencia - J. Mangas (coords.), El Edicto del Bierzo: Augusto y el Noroeste de Hispania, León, 113-122.

(2001): El municipio latino: Origen y desarrollo constitucional (=Gerión Anejos. Anejo V), Madrid.

Gascou, J.

(1972): La politique municipale de l'Empire romain en Afrique Proconsulaire de Trajan à Septime-Sévère (=Collection de l'École française de Rome 8), Roma.

(1982): "La politique municipale de Rome en Afrique du Nord I. De la mort d'Auguste au début du III" siècle", ANRW II, 10.2, 136-229.

(1997): "Magistratures et sacerdoces municipaux dans les cités de Gaule Narbonnaise", [en] M. Christol - O. Masson (eds.), Actes du Xe Congrès Internationale d'Épigraphie Grecque et Latine (Nîmes 1992), (= Histoire ancienne et médiévale 42), Paris, 75-140.

González, J. (1992): Corpus de inscripciones latinas de Andalucía. Volumen II. Sevilla. Tomo IV: El Aljarafe, Sierra Norte, Sierra Sur, Sevilla (=CILA 5).

González Fernández, J. - Crawford, M. (1986): "The Lex Irnitana: a new copy of the Flavian municipal law", JRS 76, 147-243 (https://doi.org/10.3815/007543508786239535).

Goudineau, C. (1976): "Le statut de Nîmes et les Volques Arécomiques”, Révue Arquéologique de Narbonnaise 9, 105-114 (https://doi.org/10.3406/ran.1976.990).

Guarino, A.

(1987): Storia del diritto romano, Napoli.

(1994): "Gaio e l'edictum provinciale", [en] Pagine di diritto romano IV, Napoli, 279295.

Humbert, M. (1978): Municipium et civitas sine suffragio. L'organisation de la conquête jusqu'à la Guerre Sociale (=Collection de l'École française de Rome 36), Roma. 
Hurlet, F. (2006): Le proconsul et le prince d'Auguste à Dioclétien (=Ausonius Éditions. Scripta Antiqua 18), Bordeaux.

Jacques, F. (1991): “Municipia libera de l'Afrique proconsulaire", [en] Epigrafia. Actes du colloque international d'épigraphie latine en mémoire de Attilio Degrassi pour le centenaire de sa naissance, Roma, 583-606.

Kremer, D. (2006): Ius latinum: Le concept de droit latin sous la République et l'Empire, Paris.

Laffi, U. (1966): Adtributio e contributio: Problemi del sistema politico-amministrativo dello stato romano (=Studi di Lettere, Storia e Filosofia ENS 28), Pisa.

Lamberti, F. (1993): Tabulae Irnitanae. Municipalità e ius Romanorum (=Pubblicazioni del Dipartimento di diritto romano e storia della scienza romanistica dell'Università degli studi di Napoli Federico II 6), Napoli.

Lenel, O. (1927): Das Edictum Perpetuum, Leipzig.

Liddell, H. G. - Scott, R. (1968): A Greek-English Lexicon, Oxford.

López Barja de Quiroga, P. (2009): "El gobernador provincial romano de Cicerón a Plinio el Joven”, [en] M. Campagno et alii (eds.), Política y religión en el Mediterráneo antiguo, Buenos Aires, 289-304.

Luraschi, G.

(1979): Foedus, ius Latii, civitas. Aspetti costituzionali della romanizzazione in Transpadana (=Pubblicazioni della Università di Pavia. Studi nelle scienze giuridiche e sociali. Nuova serie 29), Padova.

(1983): "Sulle magistrature nelle colonie latine fittizie (a proposito di Frag. Atestinum 11. 10-12)", SDHI 49, 261-329.

Martini, R. (1969): Ricerche in tema di editto provinciale, Milano.

Millar, F. (1999): "Civitates liberae, coloniae and Provincial Governors under the Empire", Mediterraneo Antico 2, 95-113.

Mommsen, Th.

(1873): Étude sur Pline le Jeune, Paris.

(1893): Le droit public romain III, Paris.

Olmo López, R.

(2015): "Nuevas perspectivas en torno al edicto provincial en época republicana", Latomus 74/4, 939-967.

(2017): "La actuación de los procónsules de la Bética como intermediarios entre el poder imperial y las comunidades locales a inicios del Principado", Habis 48, 133-149.

(2018): El centro en la periferia: Las competencias de los gobernadores provinciales romanos en Hispania durante el Principado (=Geschichte und Kultur der Iberischen Welt 14), Zürich-Wien-Münster.

Peppe, L. (1991): “Note sull'editto di Cicerone in Cilicia”, Labeo 37, 14-93

Plácido, D. (1991): “La latinidad de Nemauso: Nota crítica a Estrabón 4.1.12: 186-7”, Studia Historica. Historia Antigua 9, 61-62.

Pugliese, G. (1964): “Riflessioni sull'editto di Cicerone in Cilicia”, [en] Synteleia ArangioRuiz, Napoli, 972-986

Roth-Congès, A. (2003): “Le statut des agglomérations secondaires de Languedoc oriental et l'oppidum latinum des Umbranici", [en] Peuples et territoires en Gaule méditerranéenne. Hommage à Guy Barruol (=Révue Archéologique de Narbonnaise, Suppl. 35), Montpellier, 549-564.

Sherwin-White, A. N.

(1966): The Letters of Pliny: A Historical and Social Commentary, Oxford. 
(1973): The Roman Citizenship, Oxford.

Sisani, S. (2018): "Le magistrature locali delle comunità municipali di ambito provinciale: uno studio sulla diffussione del quattuorvirato e del duovirato tra l'età tardo-repubblicana e l'età imperiale", Gerión 36/1, 41-77 (http://dx.doi.org/10.5209/GERI.60293).

Thollard, P. (2009): La Gaule selon Strabon: du texte à l'archéologie (=Bibliothèque d'Archéologie méditerranéenne et africaine 2), Paris.

Valiño, E. (1979): El comentario de Gayo al edicto provincial, Valencia.

Veyne, P. (1960): “Foederati: Tarquinies, Camerinum, Capène", Latomus 19, 429-436.

Vidman, L. (1960): Étude sur la correspondance de Pline le Jeune avec Trajan, Praha. 
